\title{
MALIGNANT GASTROINTESTINAL STROMAL TUMOUR AT JEJUNUM- A CASE REPORT
}

\author{
Kalpana Chandra ${ }^{1}$, Amit Kumar Sinha², Sanjeet Kumar Singh ${ }^{3}$, Shuchismita ${ }^{4}$, Anshuman Sinha ${ }^{5}$
}

${ }_{1}^{1}$ Assistant Professor, Department of Pathology, IGIMS, Patna, Bihar, India.

2Senior Resident, Department of Pathology, IGIMS, Patna, Bihar, India.

${ }_{3}^{3}$ Associate Professor, Department of Pathology, IGIMS, Patna, Bihar, India.

${ }_{4}^{4}$ Assistant Professor, Department of Pathology, IGIMS, Patna, Bihar, India.

${ }^{5}$ Senior Resident, Department of Pathology, IGIMS, Patna, Bihar, India.

HOW TO CITE THIS ARTICLE: Chandra K, Sinha AK, Singh SK, et al. Malignant gastrointestinal stromal tumour at jejunum- a case report. J. Evolution Med. Dent. Sci. 2018;7(24):2909-2911, DOI: 10.14260/jemds/2018/655

\section{PRESENTATION OF CASE}

A 44 years female, labourer by occupation, presented to our hospital with complaints of abdominal lump for 5 years, recurrent pain abdomen for past 2 years, nausea and vomiting for 2 months with generalised weakness. There was no history of constipation. She is having six live children. All were full-term normal deliveries. She has undergone hysterectomy 5 years back, but detailed documents are not available for the same.

Complete haemogram showed anaemia and other routine blood and biochemistry parameters were within normal limits. USG done outside revealed hypervascular and hypoechoic mass in the left lumbar region measuring 10 x $8 \times$ $8 \mathrm{~cm}$. Upper and lower endoscopy showed no mucosal lesions. Computed tomography (CT) showed a large heterogeneously enhancing soft tissue mass showing air specks in the left lumbar region abutting jejunum medially. No lymphadenopathy was noted. Surgical resection of the tumour was done, and operative finding revealed a mass measuring $10 \times 10 \times 9 \mathrm{~cm}$ arising from serosal surface of jejunal junction at the antimesenteric border.

Grossly, the received specimen was a segment of gut measuring $6 \mathrm{~cm}$ in length and $3 \mathrm{~cm}$ in diameter. On cut, the mucosa was largely unremarkable. Externally, on the serosal surface, a large encapsulated and well-circumscribed tumour mass was seen measuring $9 \times 9 \times 7 \mathrm{~cm}$. Outer surface was nodular. On cut, unilocular cyst with maximum diameter $9 \mathrm{~cm}$ and wall thickness $2 \mathrm{~cm}$ was seen. The cyst cavity was filled with necrotic material and surface was irregular. Microscopically, the overlying mucosa was unremarkable; however, tumour was pushing the mucosa focally. Tumour was composed of interlacing bundles and fascicles of oval to spindle atypical cells. These atypical cells show moderately pleomorphic nuclei, vesicular chromatin and indistinct cytoplasm. The underlying submucosa and muscularis propria was infiltrated by the tumour cells. Areas of cystic degeneration were seen.

'Financial or Other Competing Interest': None.

Submission 01-05-2018, Peer Review 27-05-2018,

Acceptance 02-06-2018, Published 11-06-2018.

Corresponding Author:

Dr. Amit Kumar Sinha,

Senior Resident,

Department of Pathology,

Indira Gandhi Institute of Medical Sciences,

Patna-800014

Bihar, India.

E-mail: dramit_sinha@yahoo.co.in

DOI: $10.14260 /$ jemds $/ 2018 / 655$
Tumour reached close to serosa ( $<1 \mathrm{~mm}$ away). Mitosis is 6-7/50 HPF. No necrosis seen. The proximal and distal resection margins were free.

Gastrointestinal stromal tumours are the most common mesenchymal neoplasms of the gastrointestinal tract. It can occur anywhere in the gastrointestinal tract (GIT) where stomach is the most common site and in the small intestine, jejunum is the rare site. It can be benign or malignant depending upon size and mitotic figures. Surgery is the treatment of choice. Mostly jejunal GIST are asymptomatic or present with lump abdomen. Final diagnosis is rendered only after histopathological examination and immunohistochemistry of the removed specimen. However, this term should be applied only to neoplasms expressing Ckit (CD-117) with very rare exceptions.[1] This characteristic immunophenotype has made this tumour a distinct entity, though other non-epithelial tumours of GIT like leiomyoma, leiomyosarcoma, neuromas, neurofibroma may look similar on $\mathrm{H}$ and $\mathrm{E}$ stain. It is common in 50-60 years age group.[2] It affects both men and women equally with slight male preponderance.[3] It represents about $0.3 \%$ to $3.3 \%$ of all GI neoplasm. In the gastrointestinal tract, stomach is the commonest organ to be involved followed by small intestine, colon, rectum and oesophagus, ${ }^{[4]}$ whereas jejunum is the least common site for GIST.[3] However, malignant transformation is more common in small intestine as compared to the stomach.[1] Jejunal GISTs are typically asymptomatic. Around $20 \%$ may grow large enough to present with pain or a palpable mass. ${ }^{[3]}$ We report a case of malignant jejunal GIST in a female patient, who presented with pain abdomen and a palpable lump.

\section{DIFFERENTIAL DIAGNOSIS}

Based on the microscopic examination of the $\mathrm{H}$ and $\mathrm{E}$ sections, a differential diagnosis of GIST, intestinal leiomyosarcoma, schwannoma and poorly differentiated carcinoma was made.

Immunohistochemistry of CD-117 was put, which was strongly positive and showed diffuse cytoplasmic staining with membranous accentuation. More markers were put like CD-34 (diffuse positive staining), SMA (focal positivity) and S100 (negative).

\section{CLINICAL DIAGNOSIS}

On the basis of clinical and radiological evaluation, provisional diagnosis of gastrointestinal stromal tumour was made. 


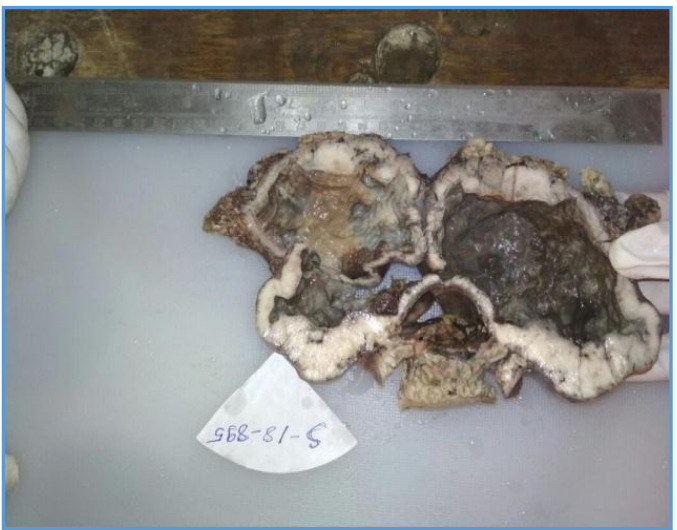

Figure 1. Gross- Cut Open Unilocular Cystic Mass Filled with Necrotic Debris

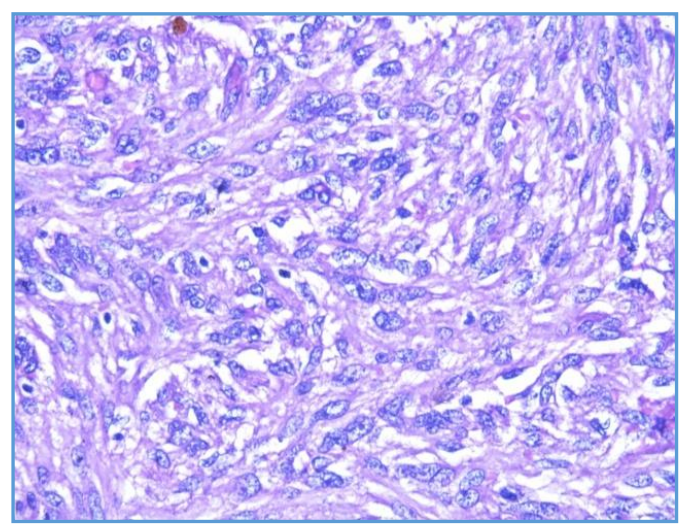

Figure 2. H and E Stain (40 x): Fascicles of Oval to Spindle Cells

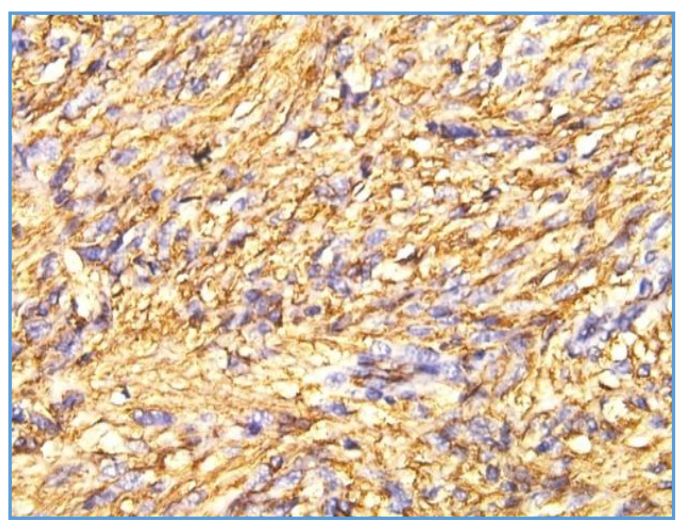

Figure 3. IHC (CD-117)- Diffuse Staining of Oval to Spindle Cells (40 x)

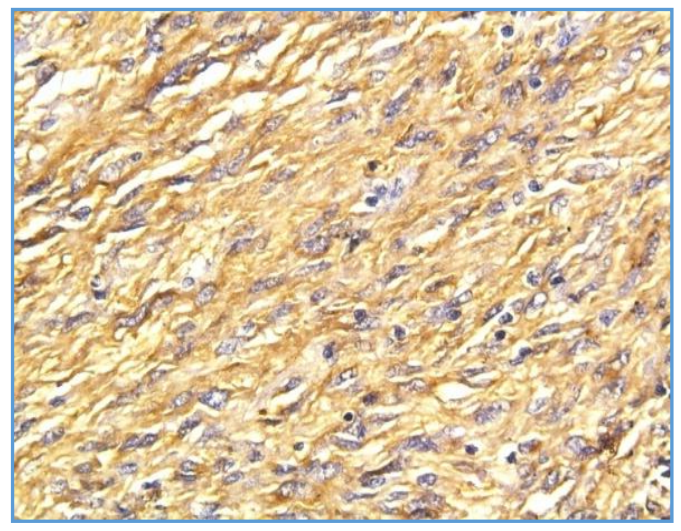

Figure 4. IHC (CD-34)- Diffuse Staining of Oval to Spindle Cells (40 x)

\section{PATHOLOGICAL DISCUSSION}

Gastrointestinal stromal tumour is the most common mesenchymal neoplasm of the alimentary tract. In year 1983, Mazur and Clark described this type of lesion as stromal tumour.[3] It has been recognised that this tumour arises from the special cells located in the muscularis propria of the wall of GI tract called interstitial cells of Cajal (ICC) or pacemaker cells. The pathogenesis of this tumour in approximately 75$80 \%$ of cases results from activating mutations of protooncogenes C-kit. In about 8\%, GIST results from an activating mutation in the gene for a different growth factor receptor called platelet-derived growth factor receptor alpha.[5]

The vast majority of GISTs occurs in a sporadic and isolated form, but can be features of multiple neoplastic syndromes. Sporadic cases of extra intestinal GIST have been documented and this occurs outside the intestinal tract. The sites include omentum, mesentery, retroperitoneum, gall bladder, pancreas, liver and urinary bladder.[3] Primary GIST of this site appears to be aggressive tumour. However, most of these cases later confirmed to be metastatic from gastric or intestinal primaries.[6]

GIST may grow intramurally involving all layers of the gut or may project outwards towards serosa, may be covered by an intact or ulcerated mucosa. Most GISTs are solitary, well circumscribed and ovoid fleshy masses. On cut section, GISTs show whorled appearance. Areas of haemorrhage or cystic degeneration may be noted in few cases like in ours. The prognosis of GIST includes size of the tumour, mitotic count and location as gastric GISTs are less aggressive than those arising in the small intestine.[5] In a study conducted by Brainard et al, on 39 cases of jejunum and ileal stromal tumour they concluded that the features associated with adverse outcome included tumour size $>5 \mathrm{~cm}$ and mitotic counts $>5$ mitosis/ 50 hpf.[7]

The morphological similarity of other spindle cell neoplasm arising in the GI tract like leiomyosarcoma, leiomyoblastoma, schwannomas and poorly differentiated carcinoma may pose diagnostic dilemma. So, definite diagnosis relies on combination of cellular morphological assessment and immunohistochemistry.

\section{FINAL DIAGNOSIS}

On the basis of morphology of cells on $\mathrm{H}$ and $\mathrm{E}$ sections and results of immunohistochemistry, the final impression of malignant gastrointestinal stromal tumour of high risk was made.

\section{REFERENCES}

[1] Cooper HS. Intestinal neoplasms. In: Mills SE, edr. Sternberg's diagnostic surgical pathology. $4^{\text {th }}$ edn. India: Jaypee Brothers Medical Publishers Ltd., 2004: p. $1589-90$

[2] Fisher C. Gastrointestinal stromal tumors. In: Pignatelli M, Underwood JCE, eds. Recent advances in histopathology 21. UK: The Royal Society of Medicine Press Ltd., 2005: p. 71-88.

[3] Kramer K, Siech M, Sträter J, et al. GI haemorrhage with fulminant shock induced by Jejunal gastrointestinal stromal tumor (GIST) coincident with duodenal neuroendocrine carcinoma (NET) + 
neurofibromatosis (NF) -- case report and review of the literature. Z Gastoenterol 2005;43(3):281-8.

[4] Miettinen M, Lasota J. Gastrointestinal stromal tumors definition, clinical, histological, immunohistochemical and molecular genetic features and differential diagnosis. Virchows Arch 2001;438(1):1-12.

[5] Turner RJ. The gastrointestinal tract. In: Kumar V, Abbas KA, Aster JC, eds. Robbins \& Cotran pathologic basis of disease. $9^{\text {th }}$ edn. Relex India Pvt Ltd., 2016: p. 775-6.
[6] Sornmayura P. Gastrointestinal stromal tumors (GISTs): a pathology view point. J Med Assoc Thai 2009;92(1):124-35.

[7] Brainard JA, Goldblum JR. Stromal tumour of the jejunum and ileum: a clinicopathologic study of 39 cases. Am J Surg Pathol 1997;21(4):407-16. 